\title{
HUBUNGAN PEMBERIAN INFORMED CONSENT DENGAN TINGKAT KECEMASAN ORANG TUA ANAK YANG DI TERAPI INTRAVENA DI RUANG UDG RSUD POLEWALI MANDAR
}

\author{
Andan Firmansyah \& Niar
}

Medical procedures performed by medical personnel at the hospital can bring a variety of risk to the patient. Anxiety is the most common response experienced by parents when there are health problems in children. Largely due to the lack of knowledge or information obtained related to the action to be performed. Informed consent is consent given medical treatment by patients or their families on the basis of the explanation of health workers. The purpose of giving informed consent in order to reduce the level of parental anxiety.The purpose of this study was to determine the relationship between the provision of informed consent by the level of anxiety of parents of children who were treated intravenously in the ED Hospital District. Polewali. This study used cross sectional design with accidental sampling technique in 30 respondents. The statistical test used is chi-square with a significance level of $p<0.000$.These results indicate that administration of informed consent have a significant relationship with the level of anxiety of parents of children who were treated intravenously with the value of significance is $p=0.000(p=<0.05)$. The conclusion of this study is that the informed consent provision related to the level of anxiety of parents of children who were given intravenous therapy in the ED. Suggestions from this study is expected to hospital management can improve the quality of health care and nursing care that all nursing staff provide informed consent in accordance with its role is to protect the rights of patients to a given action in order to minimize anxiety in the elderly.

Keywords: Anxiety, informed consent, intravenous therapy 


\section{PENDAHULUAN}

Persetujuan tindakan medik informed consent adalah persetujuan yang diberikan oleh pasien atau keluarganya atas dasar penjelasan mengenai tindakan medik yang akan dilakukan terhadap pasien tersebut. Persetujuan ini bisa secara langsung atau tidak langsung dalam bentuk lisan ataupun tulisan. Persetujuan langsung berarti pasien atau wali menyetujui usulan pengobatan atau tindakan yang ditawarkan oleh pihak pemberi layanan kesehatan. Sedangkan persetujuan tidak langsung biasa terjadi pada kasus darurat yang mengharuskan dilakukan tindakan penyelamatan terlebih dahulu (Medicalrecord, 2011).

Sebagai penerima pelayanan, hal ini berkaitan dengan hak pasien menentukan nasib sendiri (the right to self determination) sebagai dasar hak asasi manusia. Hak pasien sebagai pengguna jasa pelayanan kesehatan akan berhubungan dengan kewajiban tenaga kesehatan dan rumah sakit untuk menunaikan hak-haknya. Olehnya itu maka pemahaman tenaga kesehatan tentang hak pasien menjadi suatu keharusan. Hukum diharapkan akan melindungi kepentingan hak. Hak pasien sebagai pengguna jasa pelayanan kesehatan dan sebagai konsumen, dilindungi oleh UU No.23 Tahun 1992 tentang kesehatan, UU Praktek kedokteran No 29 Tahun 2004 dan UU No.8 Tahun 1999 tentang perlindungan konsumen. Hak pasien selalu dihubungkan dengan pemeliharaan kesehatan maka hak utama dari pasien tentunya adalah hak untuk mendapatkan pemeliharaan kesehatan (the right to health care) (Sugiarti, 2009). Dalam UU No 23 Tahun 1992 tentang Kesehatan pasal 53 dengan jelas dikatakan bahwa hak health care receiver antara lain hak atas informasi dan hak memberikan persetujuan tindakan medik atas dasar informasi (informed consent). Jadi informed consent merupakan implementasi dari kedua hak pasien tersebut (Siswosaputro, 2010). 
Persetujuan tindakan medik informed Olehnya itu maka pemahaman tenaga consent adalah persetujuan yang diberikan kesehatan tentang hak pasien menjadi suatu oleh pasien atau keluarganya atas dasar keharusan. Hukum diharapkan akan penjelasan mengenai tindakan medik yang melindungi kepentingan hak. Hak pasien akan dilakukan terhadap pasien tersebut. sebagai pengguna jasa pelayanan kesehatan Persetujuan ini bisa secara langsung atau dan sebagai konsumen, dilindungi oleh UU tidak langsung dalam bentuk lisan ataupun No.23 Tahun 1992 tentang kesehatan, UU tulisan. Persetujuan langsung berarti pasien atau wali menyetujui usulan pengobatan atau tindakan yang ditawarkan oleh pihak pemberi layanan kesehatan. Sedangkan persetujuan tidak langsung biasa terjadi pada kasus darurat yang mengharuskan dilakukan tindakan penyelamatan terlebih dahulu (Medicalrecord, 2011).

Sebagai penerima pelayanan, hal ini berkaitan dengan hak pasien menentukan nasib sendiri (the right to self determination) sebagai dasar hak asasi manusia. Hak pasien sebagai pengguna jasa pelayanan kesehatan akan berhubungan dengan kewajiban tenaga kesehatan dan Praktek kedokteran No 29 Tahun 2004 dan UU No.8 Tahun 1999 tentang perlindungan konsumen. Hak pasien selalu dihubungkan dengan pemeliharaan kesehatan maka hak utama dari pasien tentunya adalah hak untuk mendapatkan pemeliharaan kesehatan (the right to health care) (Sugiarti, 2009). Dalam UU No 23 Tahun 1992 tentang Kesehatan pasal 53 dengan jelas dikatakan bahwa hak health care receiver antara lain hak atas informasi dan hak memberikan persetujuan tindakan medik atas dasar informasi (informed consent). Jadi informed consent merupakan implementasi dari kedua hak pasien tersebut (Siswosaputro, 2010). rumah sakit untuk menunaikan hak-haknya. 
Perawat sebagai salah satu tenaga kepentingan pasien dan dapat bermanfaat kesehatan berkewajiban melaksanakan untuk pasien (PPNI 2011)

peran dan fungsinya di sarana pelayanan Segala tindakan yang dilakukan oleh kesehatan khususnya rumah sakit untuk petugas kesehatan sedikit banyaknya dapat menunaikan hak-hak pasien Hak pasien mendatangkan resiko. Tindakan medik tersebut adalah hak atas informasi dan hak memberikan persetujuan tindakan medik atas dasar informasi. Peran perawat dalam informed consent terutama adalah membantu pasien untuk mengambil keputusan pada tindakan pelayanan kesehatan sesuai dengan lingkup kewenangannya setelah diberikan informasi yang cukup oleh tenaga kesehatan (siswosaputro 2010). seperti terapi intravena merupakan suatu solusi dalam mengatasi masalah yang berhubungan dengan gangguan keseimbangan cairan dan elektrolit dalam program pengobatan. Saat pemasangan tindakan terapi intravena (pemasangan infus dan injeksi) dapat disertai dengan beberapa komplikasi seperti hematoma, infiltrasi, tromboflebitis, dan emboli udara (Syam, et.al). Walaupun tindakan terapi intravena

Setiap tindakan tenaga kesehatan harus sesuai dengan kode etik masing-masing profesi kesehatan. Perawat mempunyai kode etik yang ditetapkan oleh organisasi profesi yaitu PPNI (Persatuan Perawat Nasional Indinesia). Setiap kode etik mensyaratkan bahwa apapun yang dilakukan tenaga kesehatan harus dilakukan untuk bukan merupakan tindakan pembedahan yang berbahaya, namun secara langsung dapat mempengaruhi keutuhan jaringan tubuh. Tindakan ini menimbulkan resiko betapapun kecilnya yang memungkinkan akan mendatangkan stress bagi pasien maupun keluarganya, karena merasa 
gerakan atau aktivitas terganggu kesehatan merupakan keadaan sejahtera dari

(siswosaputro 2010).

Cemas merupakan respon yang paling umum yang dialami oleh orang tua ketika ada masalah kesehatan pada anaknya (Unimus, 2010). Reaksi cemas ini akan berlanjut bila klien atau orang tua tidak pernah atau kurang mendapat informasi yang berhubungan dengan penyakit dan tindakan yang akan dilakukan (Sawitri, 2010). Perasaan cemas ini sebagian besar disebabkan oleh kurangnya pengetahuan atau informasi yang didapatkan terkait dengan tindakan yang akan dilakukan. Dengan adanya pemberian informed consent, diharapkan mampu memberikan persetujuan atas tindakan tersebut berdasarkan informasi tentang tindakan yang dilakukan petugas kesehatan sehingga dapat mengurangi kecemasan (sawitri 2010).

Fokus utama pelayanan kesehatan adalah pasien dan keluarganya. Karena badan, jiwa, dan sosial yang memungkinkan setiap orang hidup produktif secara sosial dan ekonomis, maka defenisi kesehatan ini harus dipahami oleh tenaga kesehatan bukan hanya sehat secara fisik saja tapi juga harus diperhatikan kesehatan dari jiwa dan lingkungan sosialnya, sehingga tujuan mencapai derajat kesehatan yang optimal dapat terwujud dengan pelayanan kesehatan yang baik, salah satunya dapat dilihat dalam perwujudan informed consent.

Sasongko (2010), dalam penelitianya berjudul "perbedaan tingkat kecemasan sebelum dan sesudah diberikan informed consent di ruang anggrek RS Tugurego Semarang" dengan responden 57 orang mendapatkan hasil sebagian besar tingkat kecemasan pasien pre oprasi sebelum dibeikan informed consent adalah cemas yaitu 33 orang $(57,9 \%)$, sedangkan tingkat kecemasan pre oprasi sesudah diberikan informed consent sebagian besar adalah 
cemas ringan yaitu sebesar 37 orang $(64,9 \%)$ dengan $p$ value sebesar $0,000<0,05$.

Berdasarkan data awal yang diperoleh dari RSUD Polewali Mandar menunjukkan bahwa selama satu bulan, pasien anak yang dirawat melalui jalur UGD dan Perawatan Anak yang mendapat terapi intravena berjumlah sekitar 176 pasien anak.(Rekam Medik 2014) Setelah peneliti melakukan pengamatan secara langsung dengan tehnik wawancara langsung kepada orang tua pasian anak sebanyak 10 orang, 8 dari 10 orang tua mengatakan bahwa khawatir/cemas dengan tindakan medis yang di berikan kepada anaknya.

Peneliti tertarik mengakat masalah ini karna masalah informed consent merupakan masalah yang umum terjadi disuatu pelayanan kesehatan terutama rumah sakit dan informed consent dapat menjadi acuan hukum bila terjadi malpraktik yang dilakukan oleh tenaga kesehatan. Alasan Peneliti mengambil lokasi penelitian di
RSUD Polewali Mandar karna RSUD Polewali mandar merupakan satu-satunya rumah sakit yang terdapat di kabupaten polewali mandar dan menjadi rumah sakit pusat rujukan di kabupaten polewali mandar.

Dengan adanya masalah dan data-data di atas, peneliti tertarik untuk melakukan suatu penelitian tentang Hubungan Pemberian Informed Consent dengan Tingkat Kecemasan Orangtua Pada Anak yang Diterapi Intravena di ruang UGD dan Perawatan Anak RSUD Polewali Mandar.

\section{METODOLOGI PENELITIAN}

Pada penelitian ini menggunakan desain penelitian Cross Sectional adalah suatu penelitian untuk mempelajari dinamika kooperasi antara factor-faktor resiko dan efek, dengan cara pendekatan, observasi, atau pengumpulan data sekaligus pada suatu saat (Poin Time Apparoach) (Notoatmojo,2010). 
Populasi adalah wilayah pada penelitian ini adalah sejumlah 30 orang

generalisasi yang terdiri atas objek/subjek yang mempunyai kualitas dan karakteristik tertentu yang di tetapkan oleh peneliti untuk di pelajari dan kemudian di tarik kesimpulannya. (Sugiyono,2005)

Populasi adalah keseluruhan objek penelitian atau objek yang diteliti. Pada penelitian ini populasinya adalah semua orang tua yang anaknya diterapi intravena di UGD (Unit Gawat Darurat) RSUD Polewali Mandar.

Sampel adalah sebagian dari populasi yang diambil dengan menggunakan teknik sampling, jumlahnya di tentukan oleh rumus atau suatu formula, dengan tujuan untuk mewakili populasi dalam suatu uji oleh data dari penenlitian tertentu. (Sugiyono, 2010)

Sampel penelitian adalah sebagian yang diambil dari keseluruhan objek yang diteliti dan dianggap mewakili seluruh populasi. (Notoatmodjo, 2010) Jadi sampel tua yang anaknya di retapi intravena di ruang UGD (Unit Gawat Darurat) RSUD Polewali Mandar .

\section{HASIL PENELITIAN DAN}

PEMBAHASAN

Penelitian mengenai hubungan Pemberian Informed Consent dengan tingkat kecemasan orang tua anak yang di terapi inrtavena di ruang UDG RSUD polewali mandar, dilakukan pada 16-25 Mei 2015. Data yang diperoleh dengan menggunakan lembar kuesioner yang dibagikan kepada responden kemudian diisi.

Kemudian dilakukan pengolahan data untuk memperoleh suatu hasil penelitian, berikut ini penelitian akan menyajikan analisa univariat pada tiap variabel dalam bentuk tabel distribusi frekuensi serta analisa bivariat untuk mengetahui hubungan antara variabel independen dan variabel dependen dengan mengunakan uji statistik Kolmogrov-Smirnov. 


\section{Analisa Univariat}

\section{Distribusi responden berdasarkan kelompok usia}

Distribusi Orang Tua Anak Yang Diterapi Intravena Di Ruang UDG RSUD polewali mandar usia adalah :

Tabel 4.1 Distribusi responden berdasarkan usia Orang tua Anak yang diterapi intravena Di ruang UGD RSUD Polewali Mandar

\begin{tabular}{|c|c|c|c|}
\hline No. & Usia Orang Tua & $\begin{array}{c}\text { Jumlah } \\
\text { responden }\end{array}$ & Persentase (\%) \\
\hline 1 & $23-29$ tahun & 9 & $30,0 \%$ \\
\hline 2 & $30-35$ tahun & 4 & $13,3 \%$ \\
\hline 3 & $36-41$ tahun & 4 & $13,3 \%$ \\
\hline 4 & $42-47$ tahun & 2 & $6,7 \%$ \\
\hline 5 & $48-53$ tahun & 7 & $23,3 \%$ \\
\hline 6 & $54-59$ tahun & 4 & $13,3 \%$ \\
\hline \multicolumn{2}{|c|}{ Jumlah } & $\mathbf{3 0}$ & $\mathbf{1 0 0}$ \\
\hline
\end{tabular}

Sumber : data primer 2015

Berdasarkan tabel 4.1 diatas $36-41$ tahun sebanyak 4 orang $(13,3 \%)$, usia menunjukkan bahwa distribusi usia $42-47$ tahun sebanyak 2 orang $(6,7 \%)$, usia responden orang tua anak yang berusia $23-\quad 48-53$ tahun sebanyak 7 orang $(23,3 \%)$ dan 29 tahun sebanyak 9 orang (30,0\%), usia 30- yang berusia 54-59 tahun sebanyak 4 orang 35 tahun sebanyak 4 orang $(13,3 \%)$, usia $(13,3 \%)$. 


\section{Distribusi usia anak responden}

Tabel 4.2 Distribusi usia Anak yang diterapi intravena Di ruang UGD RSUD Polewali Mandar pada bulan Mei 2015

\begin{tabular}{|c|c|c|c|}
\hline No. & Usia Anak & $\begin{array}{c}\text { Jumlah } \\
\text { responden }\end{array}$ & $\begin{array}{c}\text { Persentase } \\
(\boldsymbol{\%})\end{array}$ \\
\hline 1 & 5-6 tahun & 9 & $30,0 \%$ \\
\hline 2 & $7-8$ tahun & 8 & $26,7 \%$ \\
\hline 3 & $9-10$ tahun & 8 & $26,7 \%$ \\
\hline 4 & 11-12 tahun & 5 & $16,7 \%$ \\
\hline & Jumlah & $\mathbf{3 0}$ & $\mathbf{1 0 0}$ \\
\hline
\end{tabular}

Sumber : data primer 2015

Berdasarkan tabel 4.2 diatas sebanyak 8 orang $(26,7 \%)$, usia 9-10 tahun menunjukkan bahwa distribusi usia anak sebanyak 8 orang $(26,7 \%)$, dan yang berusia yang diterapi intravena berusia 5-6 tahun 11-12 tahun sebanyak 5 orang $(16,7 \%)$ sebanyak 9 orang $(30,0 \%)$, usia $7-8$ tahun

\section{Distribusi responden berdasarkan tingkat pendidikan}

Tabel 4.3 Distribusi responden berdasarkan tingkat pendidikan Pada Orang Tua Anak Yang di Terapi Intravena Di Ruang UGD RSUD polewali Mandar Pada Mei 2015

\begin{tabular}{|c|c|c|c|}
\hline No. & Tingkat pendidikan & $\begin{array}{c}\text { Jumlah } \\
\text { responden }\end{array}$ & $\%$ \\
\hline 1. & SD & 12 & $40,0 \%$ \\
\hline 2. & SLTP & 3 & $10,0 \%$ \\
\hline 3. & SLTA & 7 & $23,3 \%$ \\
\hline 4. & Sarjana & 8 & $26,7 \%$ \\
\hline \multicolumn{2}{|c}{} & $\mathbf{3 0}$ & $\mathbf{1 0 0}$ \\
\hline
\end{tabular}

Sumber : Data Primer

Berdasarkan Tabel 4.3 diatas responden bervariasi dari sekolah dasar menunjukkan bahwa tingkat pendidikan hingga sarjana. Distribusi terbanyak yaitu 
pada tingkat Sekolah Dasar sebanyak 12 pendidikan SLTA sebanyak 7 responden responden $(40,0 \%)$ dan terendah pada $(23,3 \%)$ dan sarjana sebanyak 8 responden tingkat pendidikan SLTP sebanyak $3 \quad(26,7 \%)$.

responden $(10,0 \%)$. Sementara tingkat

\section{Distribusi responden berdasarkan jenis pekerjaan}

Tabel 4.4 Distribusi responden berdasarkan jenis pekerjaan Pada Orang Tua Anak Yang di Terapi Intravena Di Ruang UGD RSUD polewali Mandar Mei 2015

\begin{tabular}{|c|c|c|c|}
\hline No. & Jenis pekerjaan & Jumlah responden & \% \\
\hline 1. & URT & 21 & $70 \%$ \\
\hline 2. & PNS & 9 & $30 \%$ \\
\hline \multicolumn{2}{|l|}{ Jumlah } & $\mathbf{3 0}$ & $\mathbf{1 0 0}$ \\
\hline
\end{tabular}

Sumber : Data Primer 2015

Berdasarkan Tabel 4.4 diatas Mandar adalah URT sebanyak 21 responden menunjukkan bahwa jenis pekerjaan (70\%) dan PNS sebanyak 9 responden responden pada Orang Tua Anak Yang (30\%

Diterapi Intravena Ruang UGD Polewali

\section{Distribusi responden menurut Informed Consent}

Tabel 4.5 Distribusi responden informed Consent pada Tingkat Kecemasan Orang Tua Anak pada bulan Mei 2015

\begin{tabular}{|c|c|c|c|}
\hline No. & $\begin{array}{c}\text { Pemberian informed } \\
\text { consent }\end{array}$ & Frekuensi & $\begin{array}{c}\text { Persentase } \\
(\boldsymbol{\%})\end{array}$ \\
\hline 1. & Adekuat & 20 & $66,7 \%$ \\
\hline 2. & Tidak Adekuat & 10 & $33,3 \%$ \\
\hline \multicolumn{2}{|c|}{ Jumlah } & $\mathbf{3 0}$ & $\mathbf{1 0 0}$ \\
\hline
\end{tabular}

Sumber : Data Primer 2015 
Berdasarkan tabel 4.5 diatas terlihat orang $(66,7 \%)$, dan yang mendapat informed bahwa dari 30 responden yang diberikan consent yang tidak adekuat sebanyak 10 informed condent adekuat sebanyak 20 orang $(33,3 \%)$.

\section{Distribusi responden menurut Tingkat Kecemasan}

Tabel 4.6 Distribusi responden menurut Tingkat Kecemasan Orang Tua Anak yang di terapi intravena pada bulan Mei 2015

\begin{tabular}{|c|c|c|c|}
\hline No. & Tingkat Kecemasan & $\begin{array}{c}\text { Jumlah } \\
\text { responden }\end{array}$ & $\begin{array}{c}\text { Persentase } \\
(\boldsymbol{\%})\end{array}$ \\
\hline 1. & Ringan & 1 & $3,3 \%$ \\
\hline 2. & Sedang & 19 & $63,3 \%$ \\
\hline 3. & Berat & 10 & $33,3 \%$ \\
\hline \multicolumn{2}{|r|}{ Jumlah } & $\mathbf{3 0}$ & $\mathbf{1 0 0}$ \\
\hline
\end{tabular}

Sumber : Data Primer 2014

\section{Berdasarkan Tabel 4.6 diatas Analisa Bivariat}

menunujukkan bahwa dari 30 responden yang anaknya di terapi intravena yang memiliki tingkat kecemasan ringan sebanyak 1 orang $(3,3 \%)$, yang memiliki tingkat kecemasan yang sedang sebanyak 19 orang $(63,3 \%)$ dan yang memiliki tingkat kecemasan berat sebanyak 10 orang $(33,3 \%)$
Analisa bivariat dalam penelitiana ini adalah untuk mengidentifikasi hubungan pemberian informed consent dengan tingkat kecemasan orang tua anak yang di terapi intravena di ruang UGD RSUD Polewali Mandar.

1. Hubungan pemberian Informed Consent Dengan Tingkat Kecemasan Orang Tua Anak Yang Di Terapi Intravena Di Ruang UGD RSUD Polewali Mandar

Tabel 4.7 Hubungan pemberian Informed Consent Dengan Tingkat Kecemasan Orang Tua Anak Yang Di Terapi Intravena Di Ruang UGD RSUD Polewali Mandar 


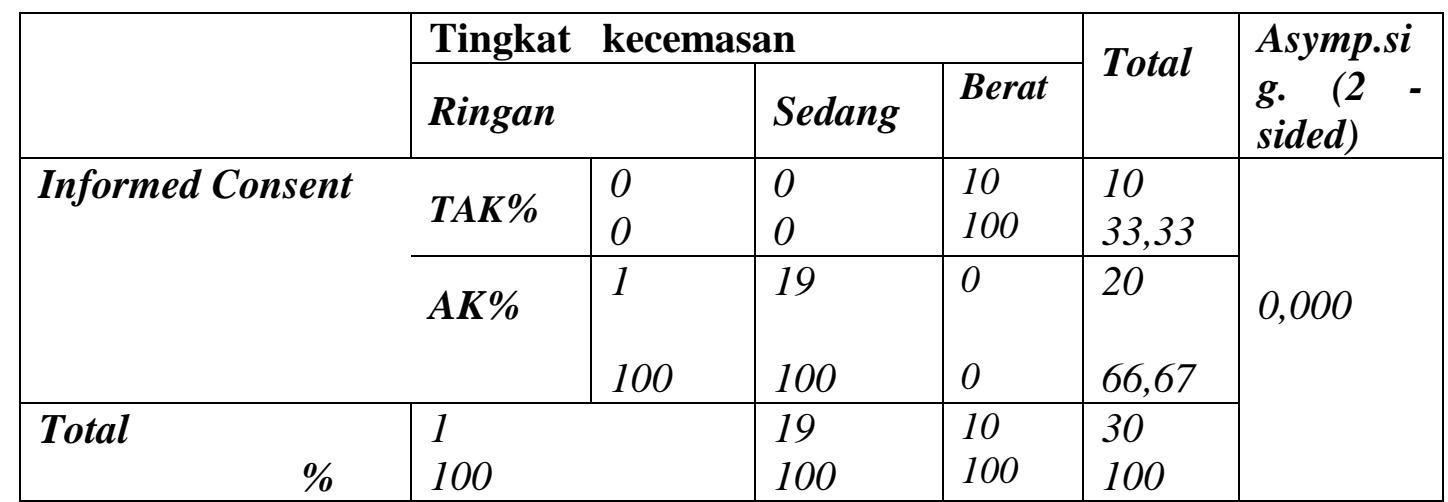

Sumber : Data Primer 2015

Distribusi responden berdasarkan sebanyak sebanyak 1 orang (100\%) hubungan pemberian Informed Consent sedangkan responden yang memiliki Dengan Tingkat Kecemasan Orang Tua informed Consent adekuat dengan tingkat Anak Yang Di Terapi Intravena Di Ruang kecemasan sedang sebanyak 19 orang UGD RSUD Polewali Mandar pada bulan (100\%) dan responden yang memiliki Mei 2015, responden yang memiliki informed Consent tidak adekuat dengan informed Consent tidak adekuat dengan tingkat kecemasan berat sebanyak 0 orang tingkat kecemasan ringan sebanyak 0 orang $\quad(0 \%)$. Berdasarkan chi-square dengan nilai $(0 \%)$, kemudian responden yang memiliki kemakmuran $\alpha=0,005$ dimana hasil informed Consent tidak adekuat dengan penelitian diperoleh $\mathrm{p}=0,000$ yang tingkat kecemasan sedang sebanyak 0 orang menunjukkan $\mathrm{p}<\alpha$ atau $0,00<0,005$. Hal (0\%) dan responden yang memliki informed ini menunjukkan bahwa ada hubungan yang Consent tidak adekuat dengan tingkat kecemasan berat sebanyak 10 orang (100\%). Responden yang memiliki informed Consent adekuat dengan tingkat kecemasan ringan signifikan antara hubungan pemberian informed consent dengan tingkat kecemasan orang tua anak yang di terapi intravena di ruang UGD RSUD Polewali Mandar. 


\section{PEMBAHASAN}

\section{Informed Consent}

Hasil analisa univariat menunjukkan

bahwa dari 30 responden terdapat 20 orang

$(66,7 \%)$ yang memiliki informed consent adekuat, dan 10 orang $(33,3 \%)$ yang

memiliki informed consent yang tidak

adekuat. Penelitian menunjukkan bahwa

informed consent adekuat lebih banyak di

banding yang tidak adekuat pada orang tua

anak yang di terapi intravena di ruang UGD

RSUD Polewali Mandar.

\section{Tingkat Kecemasan}

Hasil analisa univariat

menunujukkan bahwa dari 30 responden

yang anaknya di terapi intravena yang

memiliki tingkat kecemasan ringan

sebanyak 1 orang $(3,3 \%)$, yang memiliki

tingkat kecemasan yang sedang sebanyak 19

orang $(63,3 \%)$ dan yang memiliki tingkat

kecemasan berat sebanyak 10 orang

$(33,3 \%)$
Penelitian ini menunjukan orang tua

yang memiliki tingkat kecemasan berat, ringan dan sedang dipengaruhi oleh pemberian informent consent dan tehnik pemberian informent consent sebelum melakukan tindakan medis pada anak.

1. Hubungan pemberian informed consent terhadap tingkat kecemasan orang tua anak yang diterapi intravena di ruang UGD RSUD Polewali Mandar

Hasil penelitian menunjukan hubungan pemberian Informed Consent Dengan Tingkat Kecemasan Orang Tua Anak Yang

Di Terapi Intravena Di Ruang UGD RSUD Polewali Mandar pada bulan Mei 2015, responden yang memiliki informed Consent tidak adekuat dengan tingkat kecemasan ringan sebanyak 0 orang $(0 \%)$, kemudian responden yang memiliki informed Consent tidak adekuat dengan tingkat kecemasan sedang sebanyak 0 orang $(0 \%)$ dan responden yang memliki informed Consent tidak adekuat dengan tingkat kecemasan 
berat sebanyak 10 orang (100\%). Responden yang memiliki informed Consent adekuat dengan tingkat kecemasan ringan sebanyak sebanyak 1 orang (100\%) sedangkan responden yang memiliki informed Consent adekuat dengan tingkat kecemasan sedang sebanyak 19 orang (100\%) dan responden yang memiliki informed Consent tidak adekuat dengan tingkat kecemasan berat sebanyak 0 orang $(0 \%)$. Berdasarkan chisquare dengan nilai kemakmuran $\alpha=0,005$ dimana hasil penelitian diperoleh $\mathrm{p}=0,000$ yang menunjukkan $\mathrm{p}<\alpha$ atau $0,00<0,005$. Hal ini menunjukkan bahwa ada hubungan yang signifikan antara hubungan pemberian informed consent dengan tingkat kecemasan orang tua anak yang di terapi intravena di ruang UGD RSUD Polewali Mandar.

Penelitian tersebut sejalan dengan penelitian sebelumnya oleh Fattah (2006) yang meneliti hubungan antara pemberian informasi prosedural dengan kecemasan orang tua anak di RSUD Syekh Yusuf
Kabupaten Gowa dengan hasil penelitian terdapat hubungan bermakna antara pemberian informasi prosedural terapi intravena (pemasangan infus dan injeksi) dengan kecemasan orang tua anak ( $p=$ 0,013). Hasil yang sama juga ditunjukkan Margono (2008) dalam penelitiannya tentang pengaruh informed consent terhadap kecemasan dan pengetahuan pasien pre operasi hernia di RSUD Kabupaten Seragen dengan hasil penelitian terdapat pengaruh yang signifikan $(p=0,00)$ antara pemberian informed consent dengan kecemasan dan pengetahuan pada pasien pre operasi hernia yaitu pemberian informed consent berpengaruh terhadap kecemasan sebesar 26,2 poin lebih baik dibanding tanpa informed consent.

Hasil penelitian Mahmud (2008) juga menyatakan pemberian informed consent oleh perawat bertujuan untuk memberikan informasi tentang tindakan medik yang akan dilakukan terhadap pasien 
agar pasien/keluarga dapat mengetahui tindakan yang diberikan membahayakan atau tidak, sehingga dapat mengambil keputusan terbaik untuk dirinya.

Dalam Hanafiah dan Amir, (2008) juga menyatakan bahwa pemberian informed consent juga merupakan perwujudan disiplin dalam hukum dan profesi diantara keduanya baik dilihat dari pihak pasien maupun petugas kesehatan yaitu berfungsi melindungi pasien dari tindakan petugas kesehatan yang tidak melaksanakan tindakan sesuai dengan standar profesi, namun juga melindungi petugas kesehatan dalam menerapkan pelayanan kesehatan dari tuntutan-tuntutan yang tidak proporsional dari pihak pasien.

Dari hasil penelitian yang dilakukan ditemukan bahwa pemberian informed consent dapat mengurangi kecemasan pada orang tua yang anaknya diberikan terapi intravena, namun terdapat pula data orang tua yang diberikan informed consent namun tetap berada pada tingkat kecemasan beratsangat berat . Hal ini kemungkinan terjadi karena informasi yang diberikan kurang lengkap atau informasi sudah lengkap tetapi masih belum juga dapat dimengerti oleh pasien dan menganggap bahwa pemberian formulir informed consent hanya bagian dari administrasi yang harus ditanda tangani.

\section{KESIMPULAN DAN SARAN}

\section{Kesimpulan}

Berdasarkan hasil penelitian yang dilakukan, dapat disimpulkan :

Data dari 30 responden terdapat orang tua yang diberikan informed consent dengan adekuat oleh perawat sebanyak 20 responden dan yang diberikan informed consent secara tidak adekuat sebanyak 10 responden.

Data dari 10 responden yang memiliki informed Consent tidak adekuat dengan tingkat kecemasan ringan sebanyak 0 orang (0\%), kemudian responden yang memiliki 
informed Consent tidak adekuat dengan tingkat kecemasan sedang sebanyak 0 orang (0\%) dan responden yang memliki informed Consent tidak adekuat dengan tingkat kecemasan berat sebanyak 10 orang (100\%). Sedangkan data 20 responden yang memiliki informed Consent adekuat dengan tingkat kecemasan ringan sebanyak sebanyak 1 orang (100\%) sedangkan responden yang memiliki informed Consent adekuat dengan tingkat kecemasan sedang sebanyak 19 orang (100\%) dan responden yang memiliki informed Consent tidak adekuat dengan tingkat kecemasan berat sebanyak 0 orang $(0 \%)$.

Ada hubungan yang bermakna antara pemberian informed consent dengan tingkat kecemasan orang tua anak yang diterapi intravena di UGD Rumah Sakit Umum Daerah Kab. Polewali Mandar $(p=0,000)$

\section{Saran}

Adapun saran yang dapat diberikan berdasarkan hasil penelitian ini antara lain : Kepada semua tenaga keperawatan untuk memberikan informed consent sesuai dengan perannya sebagai advocate terhadap tindakan yang akan diberikan agar dapat meminimalkan kecemasan pada orang tua. Sebaiknya faktor-faktor seperti kondisi penyakit yang diderita anak dan pengalaman dirawat juga diteliti untuk melengkapi faktor-faktor pendukung yang dapat mempengaruhi kecemasan orang tua anak yang diberikan tindakan.

\section{DAFTAR PUSTAKA}

Arikunto, Suharsami, (2010). Posedur Penelitian Suatu Pendekatan Praktik, Jakarta : Rineka Cipta

Aziz Alimul Hidayat. (2007). Metode Penelitian Keperawatan dan Teknik Analisi Data, Jakarta : Salemba medika

Etik dalam Kedaruratan dan Pembedahan Pediatri. (Edisi Februari, 2006). Farmacia, p.36. Diakses Maret 2015 dari Grahacendikia, (2009), Kecemasan Keluarga, diakses Maret 2015 , 
Hidayat, A. Alimul. 2008. Riset Keperawatan Dan Tekhnik Penulisan Ilmiah. Edisi 3. Salamba Medika : Jakarta

Kusnadi, Darjanti, L.R., Yulianto, M. \& Mustofa. (2010). Informed Consent : Pelaksanaan Share DecisionMaking dalam Pelayanan Kesehatan. Program Megister Ilmu Kesehatan Masyarakat Konsentrasi Administrasi Rumah Sakit Universitas Diponegoro. http://eprints.undip.ac.id/1133/1/A_ 1_Informed_Consent_Journal__RS. pdf

Kusumadewi, S.,(2008). 'Aplikasi Fuzzy Total Integral Pada Hamilton Anxiety Rating Scale (HARS)', Materi dipresentasikan dalam Seminar Nasional Aplikasi Teknologi Informasi 2008 (SNATI 2008), 21 Juny 2008, Jurusan Teknik Informatika Universitas Islam Indonesia, Yogyakarta, p.73. Diakses Maret 2015 dari

Lutfah,U dan Mallya, A. (2008). Faktorfaktor Yang Mempengaruhi Kecemasan Pasien dalam Tindakan Kemoterapi di RS. Dr. Moewardi Surakarta.. Berita ilmu Keperawatan ISSN 1979-2697, Vol.1 No.4. p.187192.

M. Sopiyudin Dahlan. (2011). Statistik Untuk Kedokteran dan Kesehatan. Jakarta : Salemba Medika

Mahmud, (2010). Peran Perawat Dalam Informed Consent Pre Operasi di
Ruang Bedah Rumah Sakit Umum Pemangkat Kalimantan Barat. Diakses tanggal 12 Mei 2010.

Margono.(2008).Pengaruh Informed Consent terhadap Kecemasan dan Pengetahuan pada Pasien Pre Operasi Hernia di RSUD Kabupaten Sragen. Tesis: Program Pasca Sajana Universitas Sebelas Maret Surakarta. Diakses Maret 2015 dari http://digilib.uns.ac.id/abstrakpdf_80 04

Medicalrecord,(2009). Persetujuan Tindakan Medis . diakses Juni 2014.

$\mathrm{http}: / /$ medicalrecord.wordpress.com/ 2009/06/07

Martadisoebatra, D. (2009). Dimensi Etik Pada Informed Consent. Diakses Maret 2015. 04:34.

Notoatmodjo, Soekidjo. 2010. Metodologi Penelitian Kesehatan. Jakarta : Rineka Cipta

Pamungkas,I.Y.(2008).Pengaruh

Pendidikan Kesehatan Terhadap Penurunan Tingkat Kecemasan Pada Pasien Pre Operasi. diakses Maret 2015. 09:37 dari

Rufaidah, (2010). Efek Komunikasi Terapeutik terhadap Tingkat Kecemasan Pasien Pre Operasi di RS Haji Adam Malik Medan. Jurnal Keperawatan Vol.1. Mei 2010.

Rumila, E. (2010). Hubungan Antara Peran Perawat dengan Sikap Perawat pada Pemberian Informed Consent 
Sebagai Upaya Perlindungan Hukum bagi Pasien di RS PKU Muhammadiyah Yogyakarta. http://publikasi.umy.ac.id/index.php/ psik/article/view/2637

Romadhon, Y.A.(2006). Gambaran Klinik dan Psikofarmaka pada Penderita Gangguan Kecemasan. Diakses Maret 2015 dari http://www.ojs.lib.unair.ac.id/index. php/CDK/article/view/2774/2755

Sugiyono. 2005. Metode Penelitian Administrasi. Alfabeta. Bandung

Sawitri, (2008). Hubungan Antara Informasi Prabedah Dengan Kecemasan Pasien Pra operasi di Rumah Sakit PKU Muhammadiyah. Diakses Maret 2015.

Setiawan, T. (2009). Informed Consent antara Dokter dengan Pasien Dalam Melakukan Tindakan Medis di RSUD Seragen. Diakses Juni 2014.

http://www.etd.eprints.ums.ac.id./20 14/11/informed-censent-dokter-danpasien

Sugiarti, I. (2009). Tinjauan Filosofi dan Fungsi Perawat Dalam Pemberian Informed Consent di Rumah Sakit. Diakses tanggal Januari 2015. http://isugiarti.blogspot.com/2015/0 1/tinjauan-filosofi-peran-dan fungsi.html

Sudigdo, Sastroasmoro., Ismael, Sofyan. (2010). Dasar-dasar Metodologi
Penelitian Klinis. Ed.3. Sagung Seto: Jakarta.

Syam, Y., Sjattar, E.L., Harliani, \& Tahir, T. (2010). Penuntun Praktikum Proses Keperawatan Kebutuhan Dasar manusia II (PKKDM II). Tim Keperawatan Dasar: Makassar.

Townsend, M.C.(2010). Buku Saku Diagnosa Keperawatan Psikiatri. Ed.3. EGC: Jakarta.

Unimus (2009), Kecemasan Dan Koping Orang tua , diakses Januari 2015,http://docs.google.com/viewer $? \mathrm{a}=\mathrm{v} \& \mathrm{q}=$ cache:JOjODYB90VQJ:di gilib.unimus.ac.id/download.php\%3 Fid\%3D4490+kecemasan+orang+tu a+pada+anak+yang+sakit\&h1 
